American Journal of Applied Sciences 5 (4): 369-377, 2008

ISSN 1546-9239

(C) 2008 Science Publications

\title{
The Relationship Between National Culture and E-Adoption: A Case Study of Iran
}

\author{
Akram Hadizadeh Moghadam and Parisa Assar \\ School of Management, Shahid Beheshti University, Tehran, Iran
}

\begin{abstract}
National Culture, in the sense of the shared traditions and representations of a society, has a profound effect on the design, adoption and the use of Information Technologies in each society. EAdoption refers to the adoption of Information Technology and internet. Using Hofstede theory as the primary theoretical framework, through a review of existing studies, the current study attempted to explore the potential impact of differences in national culture on IT implementation and adoption. Based on these studies, national culture has a major effect on e-adoption; it could be as a restraining or driving force. Given the fact that the concept of culture is not static and will change over the time, this study illustrated that by renewing Hofstede's cultural dimensions, a newer attitude towards Iranian culture and its relevance with e-adoption could be achieved. In addition, the findings show that Iranian society is clustered in sense of some cultural indexes and concerning merely the average of every index, is not sufficient. Rather, it is necessary for an IT planner to provide a thorough plan which could cover each cluster of the society. To achieve this fact, we provide some propositions for e-adoption based on previous studies in other countries, to cover all of various clusters in each cultural index.
\end{abstract}

Keywords: $\quad$ National Culture, Hofstede's Cultural dimensions, VSM method, ICT adoption and implementation

\section{INTRODUCTION}

Understanding individual acceptance of IT and especially its usage is an important issue ${ }^{[1,2]}$. Iran is a country that gradually encounters with this new technology and step by step implements it in every part of its society. There are few researchers that tested the impact of cultural factors on the behavior of IT usage in Iran. Therefore, given this gap in the literature the present research aims at testing the cultural Dimensions of Iranian people which is based on Hofstede national cultural dimensions, and anticipate the behavior of Iranian people in the adoption and use of IT, which is influenced by their national culture. We intend to shed light on this research by comparing with some other countries which have been involved in researching this area before.

To achieve these goals, by explaining Hofstede's cultural dimensions, some aspects of Iranian culture in Hofstede's survey and other studies, are mentioned. Providing some empirical and theoretical studies to illustrate the relationship between national culture and ICT adoption and implementation, we intend to illustrate the importance of renewing Hofstede's cultural dimensions to obtain a reasonable comparison with other countries. We use Values Survey Module (VSM), as recommended by Hofstede ${ }^{[3]}$ for cross- cultural survey studies and distributed it among two sample societies to renew dimensions and analyze our findings based on current situation of Iran.

This analysis has a subtle difference from previous ones; we believe that Hofstede method overlooks the distribution of scores, and just emphasizes on their means. In section "Discussion and Further considerations", we present a precise analysis of this issue. Furthermore, we provide some suggestions in this section to achieve a more appropriate plan for eadoption in Iran.

Hofstede's Model Of Culture: The most common definition of culture is from Hofstede view. To Hofstede, culture is "the collective programming of the mind which distinguishes the members of one human group from another" ${ }^{[3]}$. $\mathrm{He}^{[4]}$ considers culture as the 'collective programming of the mind' and responsible for shaping the 'mental programs' or 'software of mind' in childhood.

From this view, culture means shared values, meanings, and norms within an organization or a nation. Understanding a group culture requires an extended interval considerations rather than surface manifestation of culture. By considering the core of culture, you can find how people think, and what their shared values are. Values are acquired early in life 
through childhood socialization and education, and are often "stable in nature but can change over time reflecting changes in culture" ${ }^{[5]}$. Tung's ${ }^{[6]}$ definition of culture implies that the concept is not static; rather it is dynamic and evolves over time. In this paper, the authors accentuate on the important role of time in the Iranian's culture.

Several sets of dimensions have been developed to characterize the concept of national culture. The current research will use the following dimensions: "individualism/collectivism", "power distance", "masculinity/femininity", "uncertainty avoidance" [4], and "long-term oriented/short term oriented" [7]

During 1978-83, the Dutch cultural anthropologist Geert Hofstede conducted detailed interviews with hundreds of IBM employees in 53 countries. Hofstede's Dimensions facilitates national-level analysis and are standardized to allow multiple country comparisons. His five dimensions are described below. These descriptions are mainly adopted form Hofstede's website. $^{[8]}$

PDI (Power Distance Index) is the extent to which less powerful members of a society accept unequal power distribution. Small power-distance countries, such as Norway (extremely low) and the United States (moderately low), show limited acceptance of power inequality and less dependence of subordinates on bosses. [9]

UAI (Uncertainty Avoidance Index) deals with a society's tolerance for uncertainty and ambiguity; it ultimately refers to man's search for truth. It indicates to what extent a culture programs its members to feel either uncomfortable or comfortable in unstructured situations. ${ }^{[376]}$

IDV (Individualism Index) measures the individualism of a culture. On the individualist side we find societies in which the ties between individuals are loose: everyone is expected to look after him/herself and his/her immediate family. On the collectivist side, we find societies in which people from birth onwards are integrated into strong, cohesive in-groups, often extended families which continue protecting them in exchange for unquestioning loyalty. ${ }^{[376]}$

MAS (Masculinity-Femininity), Masculinity refers to those societies, in which social gender roles are clearly distinct, and Femininity pertains to societies in which gender roles overlap. This societies value modesty, tenderness, and quality of life. ${ }^{[376]}$

LTO (Long Term Orientation) refers to the extent that people are willing to delay their needs on the short term for the benefit of the future gratifications. Values associated with Long Term Orientation are thrift and perseverance; values associated with Short Term Orientation are respect for tradition, fulfilling social obligations, and protecting one's 'face'. ${ }^{[376]}$

\section{National Culture And Information Technology Adoption: To demonstrate how Hofstede's framework might relate to ICT use, in the table 1, we provide a brief description of the relationship between each dimension and IT acceptance and adoption, based on previous researches .}

Description Of Iranian Culture: To have a depiction from Iranian National Culture, we use some studies that had been done in the Iranian organizations. Organizational studies can make us a better sense of national studies. In addition, researchers and management theorists understand organizational phenomena based, in part, on some assumptions related to their societies' cultures ${ }^{[9]}$.

Before the Islamic Republic Revolution, Hofstede's indexes were measured to the Iranian's society. Table 2 shows Hofstede's scores at the time of the survey (1972) [8]. According to Hofstede's dimensions, Iran ranked 24th among 53 countries in individualism with a small tendency to collectivism ${ }^{[8]}$. It should be emphasized that Hofstede conducted his study in organizational contexts, in subsidiaries of the IBM Company in 72 countries. Therefore, the rank of Iran in that study may not be generalized to the whole of Iranian society, which may have been more collectivistic at that time ${ }^{[10]}$. According to Hofstede, Iran ranked 27 in high power distance among 53 countries, close to the average of power distance for those countries ${ }^{[10]}$.

Recently, a study was carried out concerning leadership attributions and cultural factors in some Iranian companies. The cultural dimensions of this study were modified versions of Hofstede's dimensions of culture ${ }^{[10]}$. Societal collectivism, in-group collectivis $\mathrm{m}$, power distance, and some other cultural dimensions were considered in this study ${ }^{[12]}$. But regards to Hofstedes' dimensions, some of them haven't been considered and because of the goal of that study, it had been held survey on some special organizations. In that study, two different types of collectivism, societal collectivism and in-group collectivism were distinguished. ${ }^{[11]}$ Societal collectivism referred to "the degree to which organizational and societal institutional practices encourage and reward collective distribution of 
resources and collective action" [11]. However, in-group collectivism was defined as "the degree to which individuals express pride, loyalty and cohesiveness in their organizations or families" [11]. In-group refers to collectivism in a way that members are highly interdependent and have a sense of common fate. In contrast, groups to which they do not belong are outgroups ${ }^{[13]}$. The managers were asked to rate to what extent they believed that the cultural factors listed above 'existed' in their everyday organizational life.

According to the findings results ${ }^{[12]}$, Iranian managers reported fairly high levels of power distance and in-group collectivism. However, Iranian managers reported quite a low level of societal collectivism. That is, Iranian managers reported one of the highest ingroup collectivism with high power distance, whereas one of the lowest societal collectivism ${ }^{[12]}$. Because of high in-group collectivism, Iranians may not be likely to work cooperatively with others who may be identified as out-group members ${ }^{[10]}$.

Geert Hofstede in his website ${ }^{[8]}$ has mentioned that with the over-throw of the Shah in January of 1979, and the subsequent re-emergence into Islamic fundamentalism, the current Hofstede Dimensions for Iran may conform more closely to other Muslim countries that have higher Uncertainty Avoidance and Power Distance rankings. We will assess this anticipation in our research. In many papers, these indexes are derived from the time of last survey for Iran. Therefore, this paper will renew dimensions of culture for Iran and analyzed how they might affect acceptance and adoption of ICT among Iranian people.

\section{METHODOLOGY}

As described earlier, Hofstede's cultural dimensions were calculated about three decades ago. Tung's ${ }^{[6]}$ definition of culture implies that the concept of culture is not static; rather it is dynamic and evolves over time.

\begin{tabular}{llll}
\hline \multicolumn{4}{l}{ Table 1: Hofstede's Dimension of Culture Scales for Iran } \\
\hline PDI & IDV & MAS & UAI \\
58 & 41 & 43 & 59 \\
\hline
\end{tabular}

As our main major is to identify the relationship between Iranian's culture and the implementation of IT, we decided to recalculate these dimensions.

Our premises based on the dynamic nature of cultural dimensions, were strongly confirmed. Because as our findings will demonstrate, the political and social atmosphere at the time of the Hofstede's survey (near
Islamic Revolution of Iran, 1972), dramatically influences some dimensions.

In the subsequent sections, we describe our method, participants, the way to collect data and our analysis to obtain renewed cultural dimensions for Iran.

Method: This study builds on VSM 94 Questionnaire (Values Survey Model 1994) which was designed by Geert Hofstede [16]. To calculate five cultural dimensions, we used formulas for index calculation, mentioned in VSM's manual ${ }^{[16]}$ which was merely derived from mean scores. In the next part of our research, we will indicate that mean score is not enough to achieve accurate cultural dimensions.

Participants: The ideal number of participants is 50 [16]. Our sample consists of two separate groups. Our first sample has been selected from graduate and undergraduate university students in two accredited university in Iran. The second sample has been chosen from employees who belong to private firms with low average age. Both sample societies were involved with ICT adoption and implementation. Tables 3 and 4 show the distribution among degrees and genders for students and employees, respectively.

Data Collection: The data were collected over three months from March 2007 to June 2007. During this time, we distributed the questionnaires among the universities and organizations. Some of these questionnaires were sent via Email and some of them were in hard-copy format.

Findings: To have a good comparison between renewed dimensions and former ones, we mentioned both new ones and the old ones in table 5 .

PDI: Obviously, we can see a transition from moderate PDI to moderately low PDI. In spite of Hofstede's forecasting, this index is decreased, and has a major difference with Arab culture's PDI which is equal to 80.

Generally, countries with low power distance allow upward social mobility of its citizens and their participation in the process of decis ion making. One of the conditions for such citizen's participation would be the implementation of various communication technologies which would support and help this kind of participation happen. Therefore it could be argued that a country with a larger power distance would have a negative attitude toward implementing and using ICTs $[14]$. 
Regarding to our findings, we could conclude that students will show positive attitude toward implementing and using IT, which could reduce ruled based processes and actually make many processes personalized. This fact also, will be supported with individualistic morale.

Table 2: Educational and gender demographics of students

\begin{tabular}{cccc}
\hline Degrees & Number & Gender & \multirow{2}{*}{ Number } \\
Undergraduates & 31 & Male & 36 \\
Masters & 36 & Female & 34 \\
Doctorates & 3 & \\
\hline
\end{tabular}

Table 3: Educational and gender demographics of employees

\begin{tabular}{cccc}
\hline Degrees & Number & Gender & Number \\
Undergraduates & 43 & Male & 23 \\
Masters & 8 & Female & 28 \\
Doctorates & 0 & \\
\hline
\end{tabular}

Table 4: The result of our survey comparing the former one

\begin{tabular}{llllll}
\hline & PDI & UAI & IDV & MAS & LTO \\
Old survey & 58 & 59 & 41 & 43 & - \\
New survey among students & 28 & 49.6 & 103 & 101 & 52.3 \\
New survey among employees & 45 & 45.1 & 82 & 71.6 & 45.1 \\
\hline
\end{tabular}

UAI: In spite of Hofstede's anticipation about conforming to Arab culture in this index after Islamic Revolution, this dimension has been decreased.

It could be expected that countries with strong uncertainty avoidance would be slow in the adoption and use of new ICTs, while the countries on the opposite end of this scale would be leaders in implementing new ICTs and willing to take the risk of failure ${ }^{[14]}$.

IDV: It shows a profound increase in compare with the older survey. One of the main reasons for this difference, as Geert Hofstede admitted it himself ${ }^{[8]}$, is the special dominant environment around 1972, the time of Hofstede survey. We can observe that after the time of revolution in which people tend to be more collectivist than before, this cultural dimension have been increased and even among students it raises to 103. This approach emerges in collective affairs in which so many managers complain about this fact that Iranian people could not cooperate in groups. ${ }^{10]}$

An individualistic culture would pay more attention to the performance of the individual. Time management would be important and any technology that could help individuals to perform more efficiently would be highly regarded and quickly accepted. Information technologies can provide these benefits. Therefore it could be argued that the country with a strong individualistic culture would have a positive attitude toward implementing and using ICTs ${ }^{[14]}$.
MAS: As the table 5 demonstrates, Iranian Masculinity index raised drastically. One of the main reasons could be the difficult economical situations through and after the war with Iraq, which imposed rigid and harsh economic situations that many people had to work hard in order to afford their elementary needs.

To achieve a more convenient life, in a country with high masculinity, there would also be a positive attitude toward implementing ICTs if these technologies improve performance, increase the chance of success and support competition, which are all key factors of a masculine culture ${ }^{[14]}$.

LTO: The long term orientation consists of values that are more oriented towards the future, for example thrift and perseverance, being tenacious in pursuit of goals, being sensitive to social contacts and commitments. On the other hand, the short term orientation is associated with values that are more oriented towards past and present. Here, Iran has a moderate score. Therefore, probably there is no driving or restraining force towards implementation of ICT.

\section{DISCUSSION AND FURTHER CONSIDERATIONS}

We provide an accurate analysis for Iran's cultural dimensions and mention some experiences of ICT adoption in other similarcountries.

Calculating cultural dimensions from Hofstede's view are based on mean scores ${ }^{[16]}$, but not only are the mean scores important in analyzing ICT adoption, but also one shall simultaneously consider the distribution of these indexes among people (i.e. in terms of variances or standard deviations). Our approach is to cluster the sample society of this research into groups based on their index scores distributions and discuss the properties of each. We clustered our sample society by extracting different modules of multi-modular distributions, fitting Gaussian curves to each module. But more complicated methods such as PCA (Principle Component Analysis) can be used in further researches.

Power Distance Index: According to table 5, obtained PDI score for Iran, was 28 and 45 among students and employees respectively. But as fig 1(A) illustrates, it seems that the students are divided into two groups, noted as Group \#1 and Group \#2 in the figure.

Student Group \#1 has a significantly low PDI in contrast with Student Group \#2, which has a moderate PDI score.

Although it seems that employees can be considered as a single group, but the variance in this group is noticeable. Therefore, in planning for ICT in Iran, we must take into account that majority, both students and employees, have a moderate PDI of 
approximately 50, however there are some people which have a significantly low PDI.

There are valuable experiences in other countries regarding to their cultural dimensions which could be advantageous. We will discuss Japan's and Norway's experiences in this way.

Japan have a moderate PDI score (50) ${ }^{[8]}$. Aoki studied learning style of distant learners in Japan, he pointed to the two following findings. First he found out that learners prefer to be fairly passive rather than active or learner centered. Second, learners need strong direction from teachers ${ }^{[16]}$.

Norway has a moderately low PDI score (31) ${ }^{[8]}$, Sornes et. al. ${ }^{[18]}$, in their investigation, believed that in compare with U.S. having almost similar PDI (40), subordinates want to have a close working relationships with their superiors and thus they want to be involved in decisions about new technology adoptions.

From these researches we can provide these suggestions for Iran:

- $\quad$ Precise guidance for students in e-learning

- Emphasis on the teacher's role in e-learning

- Participate subordinates for ICT adoption decisions

- $\quad$ Applying ICT to have a closer relationship between the managers and their subordinators

Uncertainty Avoidance Index: Recalculating UAI based on Hofstede's method, attained scores was 49.6 and 45.5 among students and employees, which both indicate moderate UAI.

However, as Fig. 1(b) illustrates, both of our sample society can be divided into two separate groups. Although, Employee Group\#1 and Student Group\#1-as the figure demonstrates - are almost more than half of the sample societies respectively, whereas we can observe that almost less than half of the sample societies are dedicated to Employee Group\#2 and as mentioned before, Hofstede had anticipated that UAI in Iran will be similar to Arab cultures (moderately high UAI) after the Iranian revolution ${ }^{[8]}$. Employees group \#2 and student group \#2 support this forecasting, whereas employees group \#1 and student group \#1 stand against that and show some noticeable differences between Iranian culture and Arab culture.

As the adoption of a new technology is concerned with doing something new, the extent of uncertainty attached to it is also great ${ }^{[19]}$. Since people in countries with a high score on uncertainty avoidance are more riskadverse and do not like making changes (or "doing something for the first time"), it is suggested that these countries have a lower rate of ICT adoption than countries with a low UAI score ${ }^{[20]}$.

To have an acceptable comparison, we will consider countries with moderate, moderately high and high UAI. We have chosen U.S.A. (UAI=46), Thailand $(\mathrm{UAI}=64)$, Japan $(\mathrm{UAI}=92)$ and Germany $(\mathrm{UAI}=65)^{[8]}$.

There is a comparison between Thailand and USA according to their Internet shopping behavior. On uncertainty avoidance, Thailand is much higher than USA meaning it is less prone to risk taking. Internet shopping requires new behaviors which may be considered more risk-taking. According to the actual buying behavior, Thais do much less Internet shopping than the Americans ${ }^{[21]}$.

According to distant learning in Japan, students would tend to prefer well structured educational experiences, clearly explained assignments and course requirements. In Japan, students can be very concerned with getting the "right" answers rather than discussing in "shades of grey" [16].

Vishwanath ${ }^{[22]}$ looked at online auction behaviors in three countries, the USA, Germany and Japan to see if Hofstede's conclusions about their relative degree of uncertainty avoidance would be reflected in buying and selling behaviors. In each country's Ebay website the same item was sold with the same amount of information provided. The number of bids and final price of the sale item were found to be related to the uncertainty avoidance index of each country, with Japanese buyers being the most risk averse of the three groups and USA buyers being the least risk averse.

Planning for ICT adoption in Iran needs to consider both two sections with moderate and high UAI. We provide following propositions:

- Semi structured website design

- Online payment as an extra feature in internet shopping

- $\quad$ Avoiding from pure ecommerce and have a mixed of internet shopping and conventional shopping

Individualism/Collectivi sm Index: We can observe in Fig. 1(c) that fitted to our data, there is mainly one group among students and employees separately (Student Group\#1 and Employee Group \#1). Based on Hofstede method, we obtain high score on IDV for Iran (103 for students and 82 for employees). As we described before, in spite of Hofstede's survey, individualism has grown dramatically among Iranian. It has increased from 41 to 103 and 82 among students and employees respectively. The main influential factor as we depicted before is revolutionary morale among people at the time of Hofstede's survey which had led to a more collectivistic society. 

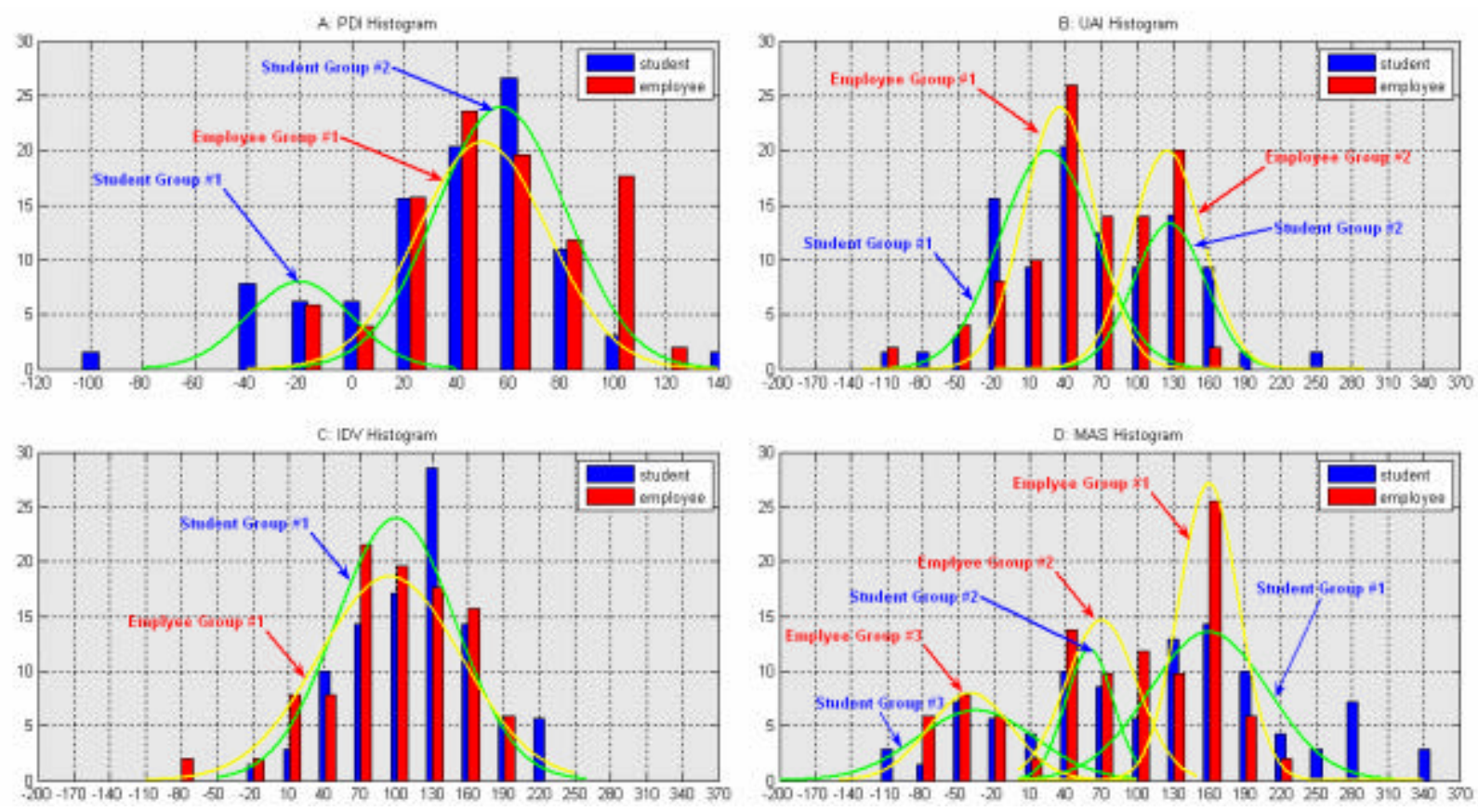

Fig. 1: Distribution of cultural indexes (A: PDI, B: UAI, C: IDV, D: MAS) among sample society.

(Vertical axis: indexes scores, horizontal axis: percent of sample societies)

This transition to individualist society has occurred in other countries. For example, in the past, Turkish people were more collectivist, but there has been a change toward individualism in recent years ${ }^{[23]}$. Either in Japan, influenced by Western cultures, people has become more individualistic ${ }^{[24]}$.

For the reason that Iran has a moderately high and high score on IDV, we have selected USA and UK to apply their experiences to Iran.

Muthitacharoen and Palvia believe that Internet shopping compared to conventional shopping is more individualistic, thus may not be easily accepted in Thailand $(I D V=20)$ rather than USA (IDV=91) ${ }^{[21]}$.

Harris et al. conducted a research about adoption of mobile-commerce based on cultural differences in UK and Hong Kong. They concluded that asynchronous mobile communication services (like SMS, MMS, Mobile Payments, Banking services) will be more popular in the UK's individualist culture (IDV=89) than in Hong Kong's collectivist culture (IDV=25). ${ }^{[25]}$

Another instance is privacy. Privacy is a typical issue in individualistic cultures ${ }^{[26]}$. So, in USA it is observed that main themes in the public record increased. Initially, issues such as social security fraud protection, personal ID protection, network security, password protection and ATM machine protection were the important areas. But as Prospective Adopters of epassports are being asked to sacrifice individual privacy for collective security, in the US society seems unlikely to accept blindly a proposal for a biometrically secured ID card and is likely to favor involvement in the decision making process ${ }^{[27]}$.

According to above researches we provide below recommendations:

- Expanding Mobile Commerce

- Using security applications in the design of a website to ensure the users

- Consideration of privacy as an important factor in the website design

Masculinity/Femininity Index: From VSM method, renewed MAS index for Iran is 101, 71.6 for students and employees respectively.

The importance of variance and standard deviation rather than mean scores will be drastically crystallized in this index for Iran. From this view, as fig. 1(D) depicted, we can divide Iran based on MAS index into three groups for each sample society. Group \#1 for both students and employees indicates severely high score on MAS, Group \#2 for both students and employees, is symptomatic of relatively high score on MAS. At last, Group \#3 for both students and employees illustrates a notably low score on MAS. None of these groups in according to their volume of the society could be ignored. Table 6, illustrates this distribution among sample society. 
Regarding to this extensive spectrum, for ICT adoption, we can use some technologies which will interest all these groups. Email could be perceived as useful to both masculine and feminine groups. While masculine individuals may use email for improving task performance, the feminine individuals may use it and support relationship building and improve the quality of the work environment ${ }^{[28]}$. Also, some researchers believe that the masculinity/femininity dimension could have at least at the conceptual level a mixed impact on the ICTs. Some authors, such as Bagchi et. al., [29] argued that "Information Systems promote more cooperation at work, better quality of life and these values are espoused in nations with low MAS index". However, it could be argued equally well that in a country with high masculinity there would also be a positive attitude toward implementing ICTs if these technologies improve performance, which would increase the chance of success and support competition, which are all key factors of a masculine culture ${ }^{14]}$.

From this view, this variety in MAS/FEM index for Iran could not play a preventive role in ICT adoption.

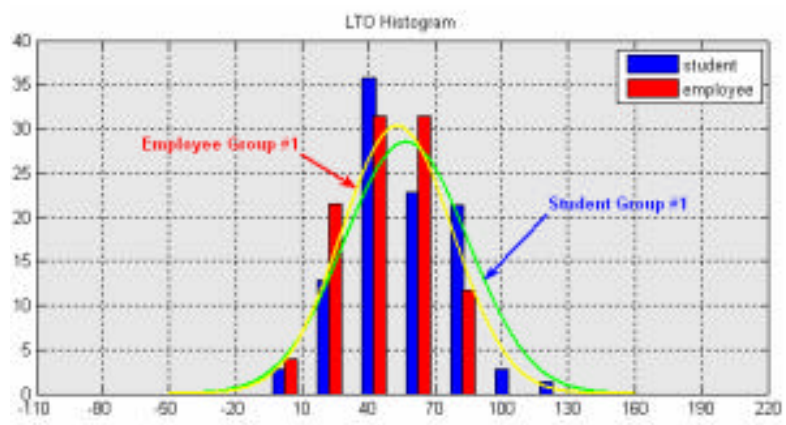

Fig. 2: Distribution of LTO among sample society. (Vertical axis: index scores, horizontal axis: percent of sample societies)

Here are some suggestions in implementation of ICT based on MAS index:

- Using both one-way communications such as fax and email and two-way communications such as online discussion groups

- Try to increase both performance and cooperation with ICTs

Long Term Oriented Index: Likewise IDV index, there is mainly single group among students and employees separately (Student Group\#1 and Employee Group \#1 as in fig. 2).

Based on Hofstede's Method obtained LTO for Iran was 52.3 and 45.1 for students and employees respectively. There was no LTO index for Iran before this research. This moderate LTO could lead us to some ICT planning which is neither very short term nor very long term.

We had a limitation in accessing countries having LTO scores in our research. We provide some of these countries with their experiments. In USA, for example, there was an empirical study which asserts that perceived near-term usefulness has a more insignificant influence on intention to use than perceived long-term usefulness in a US sample $(\mathrm{LTO}=29)^{[30]}$.

According to Veiga's view, there are some questions that each manager must consider when implementing IT based on time orientation (short term or long term): 1. Is IT perceived to be new and unpredictable or proven and reliable? 2. Are the benefits of new IT seen to be related to immediate or future work needs? 3. How does the new IT fit with valued, traditional work practices? 4 . Is the quality of strategic IT planning affected by the short-term orientation of potential users? ${ }^{[15]}$

Based on the obtained LTO, items below can take into accounts in the e-adoption:

- Try to highlight both immediate and future impact of ICTs for users

- Focus on strategic as well as operational planning in ICT planning

\section{CONCLUSION}

Evidence from the literature and empirical studies suggests that the important factor limiting the adoption of ICT in one country is national culture. After defining culture and its dimensions fom Hofstede's point of view, we tried to depict the culture of Iran. There have been many researches in order to analyze the ICT adoption based on national culture. We summarized some of these studies in our paper.

We had two distinct sections in our research: First, because of the last survey on Iran was about 35 years ago, we renewed the cultural dimensions of Iran based on Hofstede's VSM method. The results of the survey were dramatically different from the previous one.

Second, we had a critical view to Hofstede's method which is based on solely mean scores of data, disregarding their distribution. Hence, to achieve a more accurate analysis, we clustered our sample society and fitting Gaussian curves to histogram in addition to previous analysis which was purely based on Hofstede's Method. It was observed that there are somehow distinct groups of people in some dimensions and considering merely the mean score is not sufficient. 
Some of other countries' experiences were also given in order to provide guidance for organizations to plan for ICT adoption. These experiences covered a wide range of e-adoption implications.

We hope that we could demonstrate an accurate image of Iranian culture for future ICT planning in that country.

\section{REFERENCES}

1. Melone, N. P., 1990. A theoretical assessment of the user-satisfaction construct in information systems research. Management Science, 36 (1): 7691.

2. Davis, F. D., 1989. Perceived usefulness, perceived ease of use and user acceptance of information technology. MIS Quarterly, 13 (3): 319-340.

3. Hofstede, G., 1980. Cultures consequences: International differences in work-related values. Beverly Hills, CA: Sage Press. p. $260-283$.

4. Hofstede, G., 1997. Cultures and Organizations: Software of the Mind. New York, NY: McGrawHill.

5. Karahanna, E., R. Evaristo, and M. Srite, 2005. Levels of culture and individual behavior: An integrative perspective. Journal of Global Information Management, 13(2), 1-20.

6. Tung, R.L., 1995. "International Organizational Behavior." In F. Luthans (Ed.) Virtual O.B. Electronic Data Base. New York: McGraw-Hill Inc., 487-518.

7. Hofstede, G. and M. Bond, 1988. The Confucius connection: from cultural roots to economic growth. Organizational Dynamics, 16(1), 4-21.

8. http://www.geert-hofstede.com/

9. Hofstede, G., 1993, Cultural constraints in management theories, Academy of Management Executive, 7, 81-94.

10. Alavi, S. B., J. McCormick, 2003. Some cultural considerations for applying the Learning Organization model to Iranian organizations. Presented in 2003 Tehran International Management Conference. Available at: http://www.members.tripod.com/babak_alavi/Iranc onf.pdf

11. House, R., M. Javidan, P. Hanges, , and P. Dorfman, 2001. Project GLOBE: An introduction, Applied Psychology: An International Review, 50, 489-505.
12. Dastmalchian A., M. Javidan, K. Alam, 2001. Effective leadership and culture in Iran: An empirical study, Applied Psychology: An International Review 50 (4), 532-558.

13. Triandis, H., 1995. Individualism \& Collectivism Colorado, Westview Press, 52-70

14. Kovacic Z. J., 2005. The impact of national culture on worldwide eGovernment Readiness. Informing Science Journal, 8, 143-158.

15. Veiga, J.F., S. Floyd, and K. Dechant, 2001. Towards modelling the effects of national culture on IT implementation and acceptance. Journal of Information Technology, 16 (3)3, 145-158.

16. http://feweb.uvt.nl/center/hofstede/VSM.html

17. Aoki k., E. Bray, Learning Styles of Distance Learners in Japan: Cultural Considerations Available at: http://aide.nime.ac.jp/research/ Aoki\%20\&\%20Bray.pdf .

18. Sørnes, JO., KK. Stephens, AS. Sætre, LD. Browning, 2004. The Reflexivity between ICTs and Business Culture: Applying Hofstede's Theory to Compare Norway and the United States. Informing Science Journal, 7, 1-30.

19. Stoneman, P., 2001. Technological Diffusion and the Financial Environment, working paper, University of Warwick. Available at: http://www.intech.unu.edu/publications/eifc-tfpapers/eifc01-3.pdf

20. Erumban A. A., and S. B. De Jong, Cross-country differences in ICT adoption, A consequence of Culture? Available at: http://som.eldoc.ub.rug.nl/ FILES/reports/themeC/2005/05C01/05c01.pdf

21. Muthitacharoen, A., P. Palvia, 2002, B2C Internet Commerce: A tale of two nations. Journal of Electronic Commerce Research, 4(3), 201 - 212.

22. Vishwanath, A., 2003. Comparing online information effects: A cross-cultural comparison of online information and uncertainty avoidance. Communication Research, 30 (6), 579-598.

23. Aoki K., C. H. Aydin, 2006, culture collaboration and mediated communication: A case study of Turkish and Japanese' perceptions about crosscultural online collaboration. Proceeding for $2^{\text {nd }}$ International Open and Distance Learning (IODL) Symposium. 315-326. Available at: http://aide.nime.ac.jp/research/IODL2006Aoki\&Ay din.pdf

24. Spector, P.E., C.L. Cooper, and K. Sparks, 2001. An International Study of the Psychometric Properties of the Hofstede Values Survey Module 1994: A Comparison of Individual and Country/Province Level Results. Applied Psychology: An International Review, 50(2), 269281. 
25. Harris P., R. Rettie, CC. Kwan, 2005. Adoption and Usage of M-Commerce: A Cross-Cultural Comparison of Hong Kong and the United Kingdom. Journal of Electronic Commerce Research, 6(3), 210-224.

26. Hofstede G., M. de Mooij, 2002. Convergence and Divergence in Consumer Behavior: Implications for International Retailing. Journal of Retailing, 78(1), 61-69.

27. Kruelle G. Ng., P. Swatman, F. Hampe, D. Rebne, 2005, Biometrics and E-Identity (E-Passport) in the European Union: Overcoming POC-Cultural Diversity For Common Cause? IADIS International Conference: e-Society.

28. Linjun H., 2003. The Impact of Cultural Values on Email Acceptance: Evidence from the PRC, Lingnan University. The Doctorate Thesis. Available at: http://www.library.ln.edu.hk/ethesis/ huang_031106.pdf

29. Bagchi, K., R. Cerveny, P. Hart, and M. Peterson, 2003. The influence of national culture in information technology product adoption. In Proceedings of the Ninth Americas Conference on Information Systems, 957-965.

30. Chau, P.Y.K., 1996. An empirical assessment of a modified technology acceptance model. Journal of Management Information Systems, 13(2), 185-204.

31. Hasan, H, and Ditsa, G, 1999. The impact of culture on the adoption of IT: an interpretive study. Journal of Global Information Management, 7(1), 5-15.
32. Srite, M. D., 2000. The Influence of National Culture on the Acceptance and Use of Information Technologies: An Empirical Study. Doctoral Dissertation. The Florida State University.

33. Hill, C.E., Loch, K.D., Straub, D.W. and ElSheshai, K., 1998. A qualitative assessment of Arab culture and information technology transfer. Journal of Global Information Management, 6(3), 29-38.

34. De Mooij, M., 2000. The future is predictable for international marketers: Converging incomes lead to diverging consumer behavior. International Marketing Review, 17 (2), 103-113.

35. Straub, D.W., 1994. The effect of culture on IT diffusion: Email and FAX in Japan and the U.S. Information Systems Research, 5(1), 23-47.

36. Short, J., Williams, E. and Christie, B., 1976. The Social Psychology of Telecommunications, Wiley, London.

37. Tayeb, M., 1994. Organizations and national culture: Methodology considered. Organization Studies, 15(3), 429-446.

38. Hofstede, G., 2000. The information age across cultures. Proceedings of 5th AIM conference, Information Systems and Organizational Change.

39. Zahedi, F. M., Van Pelt, W. V., \& Song, J., 2001. A Conceptual Framework for International Web Design. IEEE Transactions on Professional Communication, 44(2), 83-103. 